\title{
A educação supletiva nas Campanhas de Jovens e Adultos no Brasil e em Portugal (Século XX)
}

\author{
Marta Maria de Araújo Araujo \\ Universidade Federal do Rio Grande do Norte | Brasil \\ Joaquim Luís Medeiros Alcoforado \\ António Gomes Ferreira \\ Universidade de Coimbra | Portugal
}

\section{Resumo}

Este artigo pretende apreender princípios, preceitos teóricos, materiais de ensino e aprendizado, e ainda, procedimentos didáticos, pedagógicos e educativos intrínsecos à Campanha de Educação de Jovens e Adultos, oficializada no Brasil (1947-1949) e à Campanha Nacional de Educação de Adultos, oficializada em Portugal (1952-1954). O trabalho de cunho histórico está alicerçado pelo procedimento histórico-comparativo conforme a teorização de Clarice Nunes (2001) consiste em compreender e explicar as lógicas sobre as quais as singularidades e as diversidades operam numa perspectiva mais global. Em termos de conclusão, a educação primária supletiva no Brasil e em Portugal mediante as Campanhas de Jovens e Adultos necessariamente legitimaria e efetivaria os princípios e as proposições de caráter universal dos organismos internacionais, em particular, Organização das Nações Unidas para a Educação, a Ciência e a Cultura (Unesco).

Palavras-chave: Campanha de Educação de Jovens e Adultos no Brasil e Portugal. Educação supletiva. Organismos internacionais

\section{The continuing education in the youth and adult campaigns in Brazil and Portugal (XX Century)}

\section{Abstract}

This paper intends to make apprehension of principles, theoretical precepts, teaching and learning materials, and still, learning, teaching and pedagogical procedures intrinsic to the Youth and Adult Education Campaign, made official in Brazil (1947-1949) and the National Campaign for Adult Education, made official in 
Portugal (1952-1954). The historical nature of work is underpinned by historical and comparative procedure as theorizing Clarice Nunes (2001) consists in understand and explain the logic on which the peculiarities and diversities operate in a more global perspective. In terms of conclusion, the continuing elementary education in Brazil and in Portugal, through the Youth and Adult Campaigns, necessarily would legitimize and would put into effect the universal principles and propositions of international organizations, in particular the United Nations Educational, Scientific and Cultural Organization (Unesco).

Keywords: Youth and Adult Education Campaign in Brazil and Portugal. Continuing education. International organizations.

\section{La educación continua en las campañas de jóvenes y adultos en Brasil y en Portugal (del siglo XX)}

\section{Resumen}

Este artículo tiene la intención de comprender los principios, preceptos teóricos, materiales de enseñanza y aprendizaje, y aun, el aprendizaje, la enseñanza y los procedimientos educativos intrínsecos a la Campaña de Educación de Jóvenes y Adultos, oficializada en Brasil (1947 a 1949) y la Campaña Nacional para la Educación de Adultos, oficializada en Portugal (1952-1954). La naturaleza histórica de la obra se basa en el procedimiento histórico y comparativo según la teorización de Clarice Nunes (200 1) consiste en comprender y explicar la lógica en la que las particularidades y diversidades operan en una perspectiva más global. En termos de conclusión, la educación primaria complementaria en Brasil y en Portugal por medio de las campañas de jóvenes y adultos a necesariamente legitimaría y afectaría los principios y proposiciones universales de las organizaciones internacionales, en particular la Organización de las Naciones Unidas para la Educación, la Ciencia y la Cultura (Unesco).

Palabras clave: Campaña de Educación de Jóvenes y Adultos en Brasil y Portugal. La educación continua. Las organizaciones internacionales.

\section{Introdução}

Os anos que imediatamente se seguiram à Segunda Guerra Mundial (1939-1945) fizeram eclodir a institucionalização de diversos organismos internacionais, a exemplo da Organização das Nações Unidas IONU, 
fundada em 24 de outubro de 1945 na cidade de São Francisco, Estados Unidos, entidade que substituiu a Sociedade das Nações), a Organização das Nações Unidas para a Educação, a Ciência e a Cultura (Unesco, fundada em 16 de novembro de 1945 na cidade de Londres, Inglaterra) e a Organização dos Estados Americanos (OEA, fundada em 30 de abril de 1948 na cidade de Washington, Estados Unidos), com seus sistemas de conferências, comitês, grupos de estudos, seminários, reuniões, boletins, relatórios, publicações especializadas, pretendendo,em matéria de educação, a cooperação internacional mediante princípios e proposições de caráter universal.

No decurso da Segunda Guerra Mundial, foi realizada na Cidade do Panamá, a $1^{a}$ Conferência de Ministros e Diretores da Educação das Repúblicas Americanas (25 de setembro a 4 de outubro de 1943), promovida pela União Panamericana com o patrocínio do governo do Panamá ${ }^{1}$ De acordo com a Ata Final dessa $1^{a}$ Conferência (1944), a educação do adulto analfabeto ou semianalfabeto - um dos problemas do após-guerra - necessariamente compreenderia o desenvolvimento de requisitos culturais e profissionais para o exercício da liberdade e da responsabilidade individual, bem como requisitos inerentes à cooperação internacional em matéria de educação.

14 Para o desenvolvimento desses requisitos gerais e específicos, resoluções e recomendações foram dirigidas aos cursos de educação supletiva, a cursos de continuação para adultos e a planos e programas para o ensino do adulto com prazos mínimos, devendo, pois, a escolarização oferecida equivaler ao ensino da escola primária regular. Considerando a equalização das oportunidades educacionais, devia-se fazer, periodicamente, o recenseamento demográfico da população letrada e iletrada por grupo de idades e sexo e por regiões geoeconômicas.

Próximo ao término da Segunda Guerra Mundial (oficialmente considerada em 2 de setembro de 1945) foi promovida, na cidade de Londres, a Conferência Educacional e Cultural das Nações Unidas $11^{\circ}$ a 16 de novembro de 1945), quando foi aprovada em 16 de novembro de 1945, a Convenção de uma Organização Educativa, Científica e Cultural das Nações Unidas, que resultou na criação da Organização das Nações Unidas para a Educação, a Ciência e a Cultura (Unesco), como uma agência especializada da Organização das Nações Unidas. 
Pelo documento dessa Convenção que criava uma Organização Educativa, Científica e Cultural das Nações Unidas (1946, p. 84), os países signatários como o Brasil2 teriam como propósito primordial "[...] atingir gradativamente, pela cooperação dos povos nos domínios da educação, ciência e cultura, a paz internacional e a prosperidade comum da humanidade [...]", como assim proclamada na Carta das Nações Unidas (assinada a 26 de junho de 1945) na Conferência das Nações Unidas sobre Organização Internacional na cidade de São Francisco.

Para a materialização desse propósito primordial, firmaram-se acordos internacionais necessários e imprescindíveis para promover um vigoroso impulso à educação popular e à expansão da cultura em geral, além de promover a livre circulação de ideias tanto pela palavra como pela imagem. Assim, certamente, elevaria o ideal de igualdade de oportunidades educativas sem distinção de raça, de sexo e de diferenças econômicas. A educação para a cidadania universal elevar-se-ia como um fator de primeira ordem das coisas para principiar a mais promissora aproximação internacional de todas as nações.

Por conseguinte, um ano após a aprovação pela Assembleia Geral das Nações Unidas (representada por quarenta e oito Estados) da Declaração Universal dos Direitos do Homem( 10 de dezembro de 1948) e quatro anos da fundação da Unesco (1945), foi levada a efeito, na cidade dinamarquesa de Elsinore, a $1^{a}$ Conferência Internacional de Unesco 119 a 25 de junho de 1949) de Educação de Adultos. Essa $1^{a}$ Conferência Internacional de Unesco de Educação de Adultos reuniu vinte e um organismos internacionais e cento e seis delegados de vinte e sete países, predominantemente da Europa e da América do Norte. Há que se reconhecer o efeito simbólico da Declaração Universal dos Direitos do Homem nessa Conferência Internacional de Unesco de Educação de Adultos, especialmente quanto ao ideal comum a ser atingido por todos os povos e por todas as nações pela educação escolar, com admissão de decisões uniformes e progressivas de caráter nacional e internacional.

O Brasil - um dos países membros da Organização das Nações Unidas, signatário da Convenção que resultou na criação da Unesco - foi convidado para se fazer representar na III Conferência Geral da Organização das Nações Unidas para a Educação, a Ciência e a Cultura (Unesco) ocorrida em Beirute (outubro de 1948), na capital do Líbano. Para representar o Brasil, - Ministério das Relações Exteriores designou o professor Manoel Bergström 
Lourenço Filho. Em face da exposição dos resultados de aproximadamente quinhentos mil (500.000) brasileiros alfabetizados através da Campanha de Educação de Jovens e Adultos, a Organização das Nações Americanas e a Unesco designaram o governo brasileiro como patrocinador do VI Seminário Interamericano de Alfabetização e Educação de Adultos.

$\bigcirc$ VI Seminário Interamericano de Alfabetização e Educação de Adultos - patrocinado pelo governo brasileiro promotor da Campanha de Educação de Jovens e Adultos no Brasil e promovido pela Organização das Nações Unidas para a Educação, a Ciência e a Cultura (Unesco) e a Organização das Nações Americanas e União Panamericana, com a colaboração da Organização Internacional do Trabalho (OIT), da Organização Mundial da Saúde (OMS), do Escritório Internacional de Educação de Genebra (dirigido por Jean Piaget), do Instituto Brasileiro de Educação, Ciência e Cultura (Comissão Nacional da Unesco no Brasil) - teria sido realizado na cidade brasileira de Petrópolis, Estado do Rio de Janeiro (27 de agosto a 3 de setembro de 1949), reunindo técnicos de educação de adultos (Guatemala, México, Venezuela, notadamente), delegados, observadores e técnicos internacionais de países americanos, além de países europeus (como Portugall) e 16 países asiáticos.

V VI Seminário Interamericano de Alfabetização e Educação de Adultos à semelhança dos anteriores e congêneres efetuaria por meio dos especialistas convidados - conforme notas e informações do VI Seminário Interamericano de Alfabetização e Educação de Adultos (1949, p. 32) - uma reciprocidade das ideias pedagógicas inovadoras pelo confronto dos planos exercitados pela educação primária de jovens e adultos, além do aprofundamento das bases teóricas "[...] para as campanhas e técnicas modernas de alfabetização convertida em instrumento favorável à saúde, à convivência em sociedade, à realização da democracia, ao emprego nobre dos lazeres, ao melhoramento do trabalho, à conservação dos recursos naturais".

Pela documentação do VI Seminário Interamericano de Alfabetização e Educação de Adultos, as principais indicações de temas de leituras escolares sugeridas pelos especialistas convidados para os jovens e os adultos moradores da zonas urbanas e rurais aprenderem a ler e permaneces sem lendo, seriam aqueles que proporcionassem conhecimentos elementares sobre civismo e vida social; nutrição, natureza e conservação de recursos naturais; 
melhoramento do trabalho agrícola; sociedade, indivíduo e saúde; direito social, seguros sociais; cooperativas, habitações, crédito popular.

Concomitante aos temas de leituras escolares, apareciam as indicações dos materiais didáticos e procedimentos pedagógicos (cartilhas, livros, artes plásticas, peças de teatro, audiovisual como o cinema, quadros murais, publicações), instituições culturais (bibliotecas populares, associações culturais e cívicas), igualmente recomendados para a educação de jovens e adultos pelos especialistas convidados pelos organismos internacionais.

A especialista em leitura para adultos, que aprendam a ler em contexto escolar, a professora americana Ana Nolan Clark do Instituto para os Assuntos Interamericanos (no ano de 1945 esteve no Brasil, Costa Rica, Equador, Guatemala, México e Perul proferiu por convite da Unesco, a palestra de título: Critérios para a seleção ou preparação de material de leitura destinado a adultos que aprendem a ler. Os assuntos para leitura dos adultos em contexto escolar deveriam indispensavelmente - para Clark (1949, p. 2) - alcançar as mais completas vias de pensamento e formas de viver do povo. Para esse estrito alcance, deviam ser "[...] práticos e relacionados com as necessidades do próprio leitor e os de sua família. De modo geral, a saúde e a higiene são as maiores necessidades [...], além de modos de trabalho, costumes e hábitos".

Doravante, os organismos internacionais especialmente a Unesco (constituídos de comitês e comissões), com suas resoluções, recomendações, convenções e acordos internacionais em matéria de educação postulavam, imprescindivelmente, orientar ou mesmo induzir as políticas educacionais nacionais gerais e específicas uniformemente, mediante a convergência de princípios, preceitos teóricos, materiais de ensino e aprendizado, procedimentos didáticos, pedagógicos e educativos e destinatários das políticas públicas de educação de jovens e adultos.

Nas décadas de 1940 e de 1950, foram oficializadas, no Brasil, no período de dezesseis anos (1947-1963) e em Portugal no período de quatro anos (1952-1955), as Campanhas de Educação de Adultos, destinadas, particularmente, a grupos de jovens e adultos com idade entre 14 a 35 anos que não haviam frequentado a escola ou tinham abandonado precocemente.

Todavia, para os historiadores da educação do Brasil e de Portugal analisarem as políticas públicas federais e as políticas públicas nacionais de 
educação de jovens e adultos, planejadas e implementadas pelos órgãos de educação de seus países deveras induzidas pelos organismos internacionais notoriamente a Unesco, há que se pesquisar num corpus documental apropriado (legislação educacional, portarias ministeriais, acordos institucionais, despachos, relatórios, planos), para, na sua generalidade, apreender em princípios, preceitos teóricos, materiais de ensino e aprendizado,procedimentos didáticos, pedagógicos e educativos e destinatários das políticas públicas de educação de jovens e adultos, além das razões políticas e sociais intrínsecas às Campanhas de Educação de Adultos no Brasil e em Portugal. É evidente que cada um desses elementos está inter-relacionado com todos os outros.

$\bigcirc$ presente trabalho ${ }^{3}$ de cunho histórico e alicerçado pelo procedimento histórico-comparativo, conforme a teorização de Clarice Nunes (2001), consiste em compreender e explicar as lógicas sobre as quais as singularidades e as diversidades operam numa perspectiva mais global. Ao historiador da educação, Gilberto Alves (200 1, p. 164), o singular e o universal são indissociáveis "[...] e o objetos de pesquisa só são suficientemente captados quando revelam essa indissociabilidade".

A escrita do trabalho circunscreve-se aos três primeiros anos da 18 Campanha de Educação de Adultos no Brasil integralizado no Plano Geral de Ensino Supletivo (1947-1949) e da Campanha Nacional de Educação de Adultos, oficializado no âmbito do Plano de Educação Popular em Portugal (1952-1954), relativamente ao Plano efetivado pelo Serviço de Ensino Supletivo do Estado do Rio Grande do Norte (Brasil) e ao Plano de Educação Popular, efetuado pelo Serviço de Ensino Supletivo particularmente no Distrito de Coimbra e Distritos limítrofes (Portugal).

\section{Campanha de Educação de Adultos no Brasil e no Rio Grande do Norte (1947-1949)}

Brasil declara-se uma República Federativa como forma de organização do Estado Brasileiro compreendida pelas incumbências constitucionais à União, aos Estados e aos municípios na distribuição de competências legislativas, normativas e financeiras de cada ente e articulação conjunta. Pelo caráter federativo do Estado brasileiro, sucede-se o sistema federal de educação com normas nacionais, abrangendo planos e instituições sob a jurisdição da União. 
No regime do Estado Novo no Brasil (1937-1945), o presidente Getúlio Dornelles Vargas criava, no Ministério da Educação e Saúde, a Comissão Nacional de Ensino Primário, com uma das atribuições de organizar o plano de uma campanha nacional de educação de adolescentes e adultos mediante a cooperação dos poderes públicos federais, estaduais, municipais e iniciativas de particulares (Decreto-Lei no 868, de 18 de novembro de 1938).

Ainda que houvesse políticas restritas de educação primária para adultos nos Estados, Territórios e Distrito Federal (2.077 cursos e 164.487 mil alunos matriculados aproximadamente), o Censo Populacional de 1940 havia mostrado que 55\% (13.279.919, aproximadamente) do grupo de população adolescente e adulta nas idades de 18 anos e mais em todo o país encontrava-se qualificado como iletrados (aqueles que muito pouco praticavam a leitura e a escrita) e como analfabetos com variações regionais bem acentuadas. Por conseguinte, quase a metade da população ativa estaria despreparada para a vida social e econômica do país de complexidade crescente, por não the haver sido oportunizada a educação escolar na idade própria.

No governo do presidente Eurico Gaspar Dutra (1946-1951), o Ministro da Educação e Saúde, Clemente Mariani Bittencourt (1946-1950), em $1^{\circ}$ de fevereiro de 1947, instalou o Serviço de Educação de Adultos (Portaria, $n^{\circ}$ 57, de 30 de janeiro de 1947) nomeando o Diretor-Geral do Departamento Nacional de Educação, o professor Manoel Bergström Lourenço Filho, o coordenador do Plano Geral de Ensino Supletivo da Campanha de Educação de Adolescentes e Adultos Analfabetos ou "funcionalmente analfabetos" ou, abreviadamente, Campanha de Educação de Adultos.

A Campanha de Educação de Adultos, a primeira Campanha oficial e nacional de "combate" ao analfabetismo,foi promovida com a concessão de auxílios federais (como aliás, se procedeu nos Estados Unidos), visando à implantação de uma rede de cursos primário supletivo, segundo a distribuição demográfica apurada pelo Censo Populacional de 1940. Pelo caráter federativo do Estado brasileiro, a Campanha de Educação de Adultos seria organizada por meio do sistema de cooperação interadministrativa entre a União, Estados, Distrito Federal, Territórios e Municípios.

Subjacente à ideia da Campanha de Educação de Adultos, estaria, a pretensão de impulsionar uma política de educação primária supletiva para educar jovens e adultos simultaneamente às políiticas educativas para as 
crianças em idade escolar. Para esse alcance, a destinação da União latravés do Ministério da Educação e Saúde) dos recursos da quota de 25\% proveniente do Fundo Nacional de Ensino Primário (Decreto n 19.513, de 25 de agosto de 1945), com a designação de "Auxílios aos Estados, Territórios e Distrito Federal", além das dotações consignadas em rubricas orçamentárias específicas aprovadas pelo poder legislativo, observando os termos do Plano Geral do Ensino Supletivo, aprovado pelo Ministério da Educação e Saúde.

Com o pressuposto de que a educação deveria unificar realidades e ideais de igualdade de oportunidades educativas e de formação para o futuro das crianças, jovens e adultos, bem como promover um vigoroso impulso à alfabetização e à "educação popular" de jovens e adultos de base comum no período de dois ou três anos - pelo trabalho das autoridades educacionais, professores, professores "voluntários", associações civis, congregações religiosas e de empresas públicas e privadas - o Plano Geral de Ensino Supletivo da Campanha de Educação de Adultos no parecer de Lourenço Filho (1947) estaria essencialmente consentâneo com as resoluções e recomendações da Conferência da União Panamericana (1944), da Carta das Nações Unidas (1945) e, em especial, em observância às resoluções e às recomendações da 20 Unesco.

O que esse Instituto [Unesco] da Organização das Nações Unidas, está propondo se faça é, nas suas linhas capitais, o que está realizando o Ministério da Educação, com a cooperação dos Estados e Territórios e do Distrito Federal (LOURENÇO FILHO, 1947, p. 14).

O Plano Geral de Ensino Supletivo da Campanha de Educação de Adultos - tal como elaborado por Lourenço Filho e firmemente fundamentado nos preceitos teóricos, procedimentos didáticos, pedagógicos e educativos, além dos princípios de caráter universal da Unesco - teria sido, por esse educador, debatido no curso de orientação pedagógica (1949) para os professores dos cursos supletivos promovido pela Fundação Getúlio Vargas em colaboração com o Ministério da Educação e Saúde. A ideia de Lourenço Filho, constante no texto abaixo, elucida uma das recomendações da Unesco:

A Unesco (Organização das Nações Unidas para a Educação, a Ciência e a Cultura) define os objetivos dessa educação de base como sendo os que facultem, a cada homem, os elementos que permitam viver a vida mais completa e mais feliz, e de forma 
a adaptar-se com mais facilidade às modificações de seu meio (LOURENÇO FILHO, 1949, p. 123, grifo do autor).

Como previsto no Plano Geral de Ensino Supletivo da Campanha de Educação de Adultos - no dia 15 de abril de 1947 - teriam sido oficialmente instaladas dez mil e quatrocentos e dezesseis (10.416) cursos de ensino primário supletivo para educar jovens e adultos (fundamentados numa pedagogia própria) nas cidades, vilas e principais povoados de todos os municípios do Brasil, conforme os cálculos de déficits escolares apurados pelo Serviço de Estatística da Educação e Saúde (cinco vezes mais o número de cursos existentes em 1946).

Nos termos do Relatório das atividades no exercício de 1947, uma média de seiscentos e nove mil e novecentos e noventa e seis (609.996) alunos de 15 anos e mais matricularam-se nas dez mil e quatrocentos e dezesseis (10.416) cursos de ensino primário supletivo nos horários diurno e noturno, com uma média de 30 a 50 por classe de aula. Nesse ano de 1947, os recursos destinados pela União à Campanha de Educação de Adultos foram no valor de trinta e um milhões, quarenta e um mil e quatrocentos cruzeiros $\mid \mathrm{Cr} \$$ $31.041 .400)$, além de dezessete milhões ( $\mathrm{Cr} \$ 17.000 .000,00)$ da dotação consignada em rubrica orçamentária específica, aprovada pelo poder legislativo.

No segundo ano da Campanha de Educação de Adultos, conforme o Relatório das atividades no exercício de 1948, o número de cursos de ensino primário supletivo em todos os municípios brasileiros passaria para quatorze mil e trezentos e cinquenta e nove (14.359), com uma média de oitocentos mil (800.000) alunos matriculados. Por sua vez, uma parte desses cursos supletivos foi destinada aos pequenos povoados para as populações rurais; outra parte foi destinada aos alunos da $2^{a}$ série do ensino primário supletivo devido à continuação da escolarização.

Nesse ano de 1948, além dos cursos primário supletivo funcionaram cerca de três mil (3.000) cursos "de continuação" ou destinados a pessoas já alfabetizadas. Uma apreciação do coordenador da Campanha, em seu Relatório de 1948 (p. 88), era de que o "[...] o povo deseja instruir-se, que acorre às escolas que se abrem, e onde quer que se abram [...]". Nesse ano, os recursos destinados à Campanha de Educação de Adultos foram no valor de quarenta e seis milhões, novecentos e cinquenta e cinco mil $/ \mathrm{Cr} \$$ 
46.955,000,00), além de dezessete mil (Cr\$17.000.000) da dotação consignada em rubrica orçamentária específica, aprovada pelo poder legislativo.

No terceiro ano da Campanha de Educação de Adultos, segundo - Relatório das atividades no exercício de 1949, o número de cursos de ensino primário supletivo em todos os municípios brasileiros teria sido ampliado para quinze mil e duzentos (15.200), com uma média de oitocentos e trinta mil (830.000) alunos matriculados. Pelo menos, um curso primário supletivo foi implantado em escolas rurais construídas com os recursos do Fundo Nacional de Ensino Primário. Nesse ano de 1949, os recursos destinados à Campanha de Educação de Adultos foram no valor de cinquenta e três milhões (53.000.000,00) além de dezessete mil ( $\mathrm{Cr} \$ 17.000 .000)$ da dotação consignada em rubrica orçamentária específica, aprovada pelo poder legislativo.

Enquanto diretor do Instituto Nacional de Estados Pedagógicos (19381946), o professor e pesquisador Lourenço Filho - conforme o Relatório das atividades no exercício de 1947 - coordenou uma pesquisa sobre o "vocabulário mínimo do adulto" composta por uma equipe de especialistas do ensino inicial de leitura e escrita responsável por adaptar a língua portuguesa ao sistema de ensino para adultos. Por sua vez, esse "sistema" havia sido empre22 gado, incialmente, nas Filipinas (1915), posteriormente em outros países pelo missionário protestante e educador norte-americano, Frank Charles Laubach.

missionário e educador norte-americano Frank Charles Laubach concedeu os direitos de adaptação ao professor Lourenço Filho para a produção das cartilhas destinadas à aprendizagem inicial de leitura de modo rápido e satisfatório,com o auxilio de palavras-chave e do procedimento da "silabação". Pelo Relatório de Lourenço Filho (1947/1948, p. 30 e 3 1): "Em cada lição se apresentam [palavras-chaves] e que aparecem repetidas, nas lições seguintes, permite auto aprendizagem, ou descoberta de novas palavras." As Instruções aos professores de ensino supletivo orientariam o trabalho pedagógico em sala de aula.

trabalho do professor Lourenço Filho, principalmente, propiciou as bases teóricas para que a equipe de especialistas, em ensino inicial de leitura e escrita, planejasse e organizasse as primeiras cartilhas oficializadas para os cursos de ensino primário supletivo da Campanha de títulos - Ler, primeiro guia de leitura; Saber, segundo guia de leitura e Viver, guia do bom cidadão. 
As Cartilhas resumiam toda orientação educativa da Campanha: "Ler" para "Saber" e "Saber" para "Viver" mais plenamente ou melhor".

Doravante os propósitos veementemente defendidos por Lourenço Filho (1949): educar o adulto era, pois, salvar a própria vida das crianças; uma educação de base comum que igualmente propiciasse um ajustamento social proveitoso do adulto - foram, pois, editados e distribuídos aproximadamente cinco milhões (5.000.000.00) de textos impressos na forma de livros didáticos, cartilhas, cadernos, folhetos e coleção. Esse material didático destinava-se aos estudos e aprendizados da aritmética elementar, história pátria, geografia do Brasil, bem como de noções elementares de ciências, vida social e família, higiene e alimentação; noções de formação moral e cívica, noções de direitos e deveres do cidadão, noções de defesa da saúde, de trabalho e de economia, além de noções de conservação das riquezas naturais. Afinal, que materiais didáticos, em seus títulos e seus formatos, foram distribuídos para os cursos de ensino primário supletivo de todo o Brasil?

- Livros didáticos, quadros murais de palavras-chave e folhetos de títulos Guia de linguagem, Guia de matemática, Narrativas de história do Brasil, Hino do Alfabetizado e Letras do alfabeto.

Livro de título - Juca Fubá vai à cidade. Pelo trabalho de Costa $(2012)^{4}$, o livro narrava a história "desastrosa" de Juca Fubá, um"caipira analfabeto", tocador de viola que morava próximo ao Rio São Francisco e se muda para Belo Horizonte. Ele era destinado aos alunos dos cursos que já sabiam ler e escrever (possivelmente os alunos da segunda série da educação primária supletiva).

- Cartilhas, cadernos, manuais, folhetos e coleção de cartazes da "série" Educação da saúde, da alimentação e da higiene de tífulos - Guia de alimentação, Cartilha da saúde, Educação sanitária, Educação higiênica, Malária, Tuberculose, Cuidemos da criança, Cuidado da criança e Assistência e higiene da gravidez.

- Cartilhas, cadernos, folhetos, coleção de cartazes e quadros murais de palavras-chave da "série" noções básicas de vida social, família, cultura, direitos e deveres do cidadão, técnicas e melhoramento do trabalho e economia individual de títulos - Um começo de vida, O trabalho, $A B C$ do lavrador, O operário, $O$ bom caminho, $O$ analfabeto em face do direito, além dos cadernos de 
orientação técnica de títulos: Afiador, Carpinteiro, Fresador, Fundidor, Ferreiro, Latoeiro, Pedreiro, Soldador, Tirar leite com ciência.

- Livros, cartilhas, cadernos, folhetos e coleção de cartazes que, na sua maioria, compuseram os acervos das Bibliotecas Ambulantes, das Bibliotecas Populares e das Bibliotecas de Leituras Circulantes.

- Livros de títulos - Fundamentos e metodologia do ensino supletivo e Instruções aos professores de ensino supletivo.

- Para o Programa Ensino Visual da Campanha de Educação de Adultos, foram distribuídas telas portáteis, aparelhos elétricos e a querosene de projeção filmes educativos e diafilmes de títulos: Nasce uma criança, A criança no lar, A proteção à criança,A educação da saúde, Difteria e higiene, Modernas técnicas de trabalho, Registro civil e A terra também morre.

Refletindo as políticas de ensino primário supletivo para jovens e adultos de todo o Brasil, de conformidade com o Plano da Campanha de Educação de Adultos, a ideia que vem à mente é, pois, da equalização das oportunidades educacionais para mulheres e homens jovens e adultos. Conforme o Relatório das atividades, no exercício de 1950, a matrícula geral do ensino 24 primário supletivo no triênio de 1947-1949, foi de,aproximadamente, dois milhões de jovens e adultos. Quanto ao grupo de idade dos alunos matriculados, $63 \%$ pertenciam ao sexo masculino e $37 \%$, ao sexo feminino; $66 \%$ eram de 15 e 20 anos; $25 \%$ de 21 e 30 anos; $7 \%$ de 31 a 40; $2 \%$ mais de 41 anos de idade.

Assim, pelo índice de idade no quatriênio, a maioria dos alunos matriculados nos cursos supletivos era adolescentes. Por seu turno, 41,5\% dos cursos de ensino supletivo da Campanha funcionavam na zona urbana; os demais, ou seja, 58\%, em povoações e pequenos lugarejos de zonas rurais, geralmente frequentados por homens e mulheres que viviam de trabalhos rurais. Nesse triênio (1947-1949), o total dos recursos destinado pela União à Campanha de Educação de Adultos foi de cento e trinta e um milhões, duzentos e trinta e nove mil e quatrocentos cruzeiros (1 31 1.239.400,00), além de cinquenta e um mil (Cr\$ 5 1.000.000) das dotações consignadas em rubrica orçamentária específica, aprovada pelo poder legislativo.

Assim como ocorreu em todo o território nacional, a solenidade de instalação oficial dos cursos de ensino primário supletivo no Estado do Rio Grande do Norte foi no dia 15 de abril de 1947 em Natal, no Grupo Escolar 
"Isabel Gondim" do bairro das Rocas de auti com a presença do Dr. Everton Cortez, Secretário Geral do Estado; professor Severino Bezerra de Melo, Diretor do Departamento de Educação; padre Eymard L'E Monteiro, representante do Bispo Diocesano, além do professores e alunos. A cooperação da Federação Mariana da Diocese de Natal para a Campanha de Educação de Adolescentes e Adultos foi matéria do Jornal "A Ordem" publicado em Natal.

\begin{abstract}
A classe que está funcionando na Capela da Praia do Meio [sob o patrocínio da Federação Mariana] apresenta elevada matrícula de mais de cinquenta jovens e homens, os quais demonstram a melhor boa vontade em aprender. Num generoso auxílio para o êxito da classe da Capela da Praia do Meio, a Cooperativa Central de Crédito fez uma doação em carteiras, num valor de dois mil cruzeiros, afim de completar o mobiliário escolar (A COOPERAÇÃO DOS CONGREGADOS MARIANOS, 1947, p. 11.
\end{abstract}

Nesse Estado, o Serviço de Ensino Supletivo era de responsabilidade do prof. Severino Bezerra de Melo, Diretor do Departamento de Educação. Por seu turno, devido ao contingente da população analfabeta ou funcionalmente analfabeta foram assinados os Termos do Acordo Especial (2 de abril de 1947) e, logo depois, o Termo Aditivo ao Acordo Especial (3 1 de maio de 1948) entre o Ministério da Educação e Saúde (representado pelo Ministro Clemente Mariani Bittencourt) e o governo do Rio Grande do Norte (representado pelo Interventor Federal, Orestes da Rocha Lima) para a implantação imediata de duzentos e sessenta (260) cursos de ensino primário supletivo em todos os municípios.

Nos termos dos Relatório das Atividades de 1948 e 1949, o Rio Grande do Norte apresentava os seguintes dados e avanços: Em 1947, havia 317 cursos primário supletivo, distribuídos nos núcleos urbanos e rurais municipais, 333 professores, 18.532 adolescentes e adultos matriculados e 12.960 a frequência média. Em 1948, havia 470 cursos de $1^{a}$ e $2^{a}$ séries do ensino primário supletivo, 387 professores, 19.304 adolescentes e adultos matriculados e 13.673 a frequência média. Em 1949, o Rio Grande do Norte, pela taxa de distribuição dos cursos de ensino primário supletivo, ascendeu para quinhentos 500 cursos primário supletivo de $1^{a}, 2^{a}$ e $3^{a}$ séries nos quarenta e dois (42) municípios, 387 professores, quase 21.000 adolescentes e adultos matriculados e 16.285 a frequência média. 
De acordo com as pesquisas de Araújo e Alcoforado (2015), os municípios com maior quota de classes de ensino primário supletivo eram: a capital Natal (13), Santa Cruz (1 3), Nova Cruz (1 1), Santana dos Matos (10), Santo Antonio (1 1), São José de Mipibu (10), Açu (9), Ceará-Mirim (9), Currais Novos (9), Macaíba (9), Mossoró (9), Baixa Verde (8), São Gonçalo (8), Caicó (7), Goianinha (7), Macau (7) e São Tomé (7).Igualmente pelas pesquisas de Araújo e Alcoforado (2015), no decorrer dos anos de 1948 e 1949, o Correio Aéreo Nacional transportou os seguintes livros didáticos, cartilhas, cadernos, folhetos e coleções para o Rio Grande do Norte.

- Cartilhas para os cursos de ensino primário supletivo da Campanha de títulos - Ler, primeiro guia de leitura (20.000), Saber, segundo guia de leitura (7.800) e Viver, guia do bom cidadão (1.400). Conforme já ressaltado, as cartilhas resumiam toda a orientação educativa da Campanha: "Ler" para "Saber" e "Saber" para "Viver" mais plenamente ou melhor".

- Cartilha e manuais de títulos: Guia de alimentação (5.450), Cuidemos da criança (4.250) e Começo de vida (250).

- Folheto $\bigcirc$ analfabeto em face do direito (20), Coleções de quadros murais (300) e Coleções de cartazes de educação e saúde (5).

- Livros da biblioteca popular de higiene (1400), publicação periódica leitura de todos (1 .277) e o Jornal de todos (2.850).

- Instruções aos professores de ensino supletivo (600), livros de registro escolar (520) o boletim mensal do movimento das classes (994).

- Para o Programa Ensino Visual, dia filmes (49), projetores elétricos (39) e projetores a querosene (12).

Pelo Termo Aditivo lassinado em 10 de novembro de 1948 pelo Diretor do Departamento de Educação), o Estado do Rio Grande do Norte foi autorizado a receber o valor de um milhão e vinte e sete mil e quinhentos cruzeiros (Cr\$1.027,500,00) dos recursos do Fundo Nacional do Ensino Primário. No ano de 1949, foi autorizado o valor de um milhão e cinquenta e três mil e novecentos e cinquenta cruzeiros (Cr\$1 .053,950,00). Esses valores incluíam os auxílios para gratificação de pro labore a professores e auxílios complementares, concedidos pelos Termos Aditivos, assinados pelos Diretores do Departamento de Educação.

Segundo o Relatório de Lourenço Filho (1949, p. 77), concomitante com as políticas de ensino primário supletivo para jovens e adultos, teriam 
sido implementados os sistemas de escolas destinados à infância, à elevação da matrícula, à frequência e ao síndices gerais de escolaridades, bem como à melhoria das condições pedagógicas da educação. Esses progressos educacionais foram confirmados pelas autoridades educacionais de algumas das unidades federativas. Por exemplo, as autoridades do Rio Grande do Norte, Alagoas, São Paulo, Sergipe, Paraíba, Paranã, Pernambuco e Rio de Janeiro haviam declarado que o movimento de procura da escola primária "[...] nunca foi maior do que nos dois últimos anos, e, que, de modo geral, tem-se observado maior frequência média dos alunos matriculados".

Aquele pressuposto de que a educação deveria unificar realidades e ideais humanos de igualdade de oportunidades educativas e de formação para o futuro das crianças, jovens e adultos, bem como promover um vigoroso impulso à alfabetização e à "educação popular" de jovens e adultos convinha, ademais, para Lourenço Filho, concorrer para reforçar a estrutura da vida nacional em todas as suas dimensões econômicas, políticas, sociais e de fundamentação democrática. Sob tal consideração, asseverou Lourenço Filho (1949, p. 124, grifo nosso): "Onde quer que se tenha aberto um curso não têm faltado alunos; e a percentagem dos que voltam para a continuação dos estudos [...] evidencia que o ensino, que lhes é proporcionado, tem se mostrado conveniente e útil".

Acreditava Lourenço Filho (1947, p. 14, grifo nosso) que a Campanha de Educação de Jovens e Adultos possibilitaria, em futuro próximo, um Brasil mais igualitário e, mais ainda, a educação como dever do Estado é um direito de todos. Para evidenciar o alcance do caráter internacional da Campanha de Educação de Adultos no Brasil, esse educador brasileiro assim se posicionou: "O que esse Instituto da Organização das Nações Unidas [Unesco] está propondo é que se faça, nas suas linhas capitais, o que está realizando o Ministério da Educação, com a cooperação dos Estados e Territórios e do Distrito Federal."

\section{Campanha de Educação de Adultos em Portugal, no Distrito de Coimbra e Distritos limítrofes (1952-1954)}

A nação portuguesa é um Estado unitário, concernente ao plano político-jurídico, organizando, desde sempre, o seu sistema educacional nacional, 
formado por instituições educacionais públicas e particulares, numa responsabilidade de administração direta pelo Ministério da Educação Nacional. Apesar disso, o território encontrava-se, até muito recentemente, organizado administrativamente em distritos e estes, por sua vez, em municípios, nos quais, no período histórico que nos interessa para este trabalho, apenas existiam representantes do governo, cuidando, com a sua presença de proximidade, uma adequada execução das políticas planejadas centralmente.

Durante o Estado Novo em Portugal (1933-1974), caraterizado, em especial durante a presidência de António de Oliveira Salazar, no Conselho de Ministros (1933-1968),como um regime de ditadura unipessoal, de caráter nacionalista e corporativista, o Censo da Populacional de 1940 apresentou uma elevada percentagem de jovens e adultos entre 14 e 35 anos analfabetos ou semianalfabetos, atingindo um milhão em 1950. Na década de 1930 pelas pesquisas de Pires (1990) - o número médio de adolescentes e adultos, matriculados no ensino primário, se situava próximo a trinta e três mil (33.000) alunos e alunas.

A generalidade dos distritos portugueses, apresentava, no ano de 1950, índices muito elevados de analfabetismo, podendo referir-se, como 28 exemplo, os distritos de Beja (57,9\% da população era analfabetos), Portalegre $(51,2 \%)$, Castelo Branco (51,2\%), Funchal (48,9\%), Évora (48,3\%), Faro $(47,3 \%)$, Bragança $(45,8 \%)$ e Leiria $(45,4 \%)$. Diante dessas e de outras percentagens do analfabetismo em geral, o Dr. Henrique Veiga de Macedo declarou (1953, p. 22): "A existência de 2.916,600 iletrados deveria constituir, e constituiu, forte preocupação para os responsáveis." Esses indicadores eram, objetivamente, muito pouco satisfatórios, quando comparados com os dos restantes dos países europeus.

A escolaridade primária obrigatória como antídoto do analfabetismo crescente de crianças, jovens e adultos impôs às autoridades do Ministério da Educação Nacional aprovar um Plano de Educação Popular (Decreto-Lei $n^{\circ} 38.968$, de 27 de outubro de 1952), elaborado, coordenado e dinamizado pelo Subsecretário de Estado da Educação Nacional Henrique Veiga de Macedo (1949-1955) e o Ministro Fernando Andrade Pires de Lima (1947-1955). A obrigatoriedade da educação escolar para todas as idades enquanto firme decisão governamental teria preponderantemente para o Subsecretário de Estado da Educação Nacional: 
[Uma] orientação imposta pela própria natureza das causas do analfabetismo entre nós, e, em especial, pelo fato de, mormente nos meios rurais, o nosso povo, pelas condições de sua vida, pelo regime do seu trabalho e até pela força do hábito e da rotina, não sentir necessidade de aprender a ler (MACEDO, 1954, p. 22).

Os estudos das causas do analfabetismo nos seus fatores nacionais e locais associados às causas sociais, econômicas e pedagógicas; as análises das experiências desenvolvidas em outros países no "combate" ao analfabetismo e, de alguma maneira, as resoluções e as recomendações dos congressos e seminários internacionais da Unesco (por exemplo, o VI Seminário Interamericano de Alfabetização e Educação de Adultos realizado em Petrópolis, Rio de Janeiro, 1949), e ainda a literatura divulgada pela própria Unesco, necessariamente, fundamentaram uma "austera" política de educação popular com uma primazia aos cursos de educação de adultos de caráter formativo (Decreto-Lei n 38.968, de 27 de outubro de 1952).

Do ponto de vista das políticas de educação popular, o Subsecretário de Estado da Educação Nacional, Dr. Henrique Veiga de Macedo (1954, p. 42) apreciaria o Plano Nacional de Educação Popular de haver lançado "[...] o mais forte e estruturado movimento de combate ao analfabetismo e de educação popular até agora concebido em Portugal".

Os cursos de educação de adultos de caráter formativo e com fins de alfabetizar e, consequentemente, melhorar o nível educativo dos seus destinatários pelo regime da Campanha Nacional de Educação de Adultos foram criados pelo Ministério da Educação Nacional com a colaboração das Comissões Regionais da Campanha Nacional; Comissão Distrital (composta pelo governador civil, diretores dos distritos escolares, delegado do Instituto Nacional do Trabalho e Previdência, representantes da imprensa, rádio e da organização corporativa); Comissão Concelhia (formada pelo presidente da Câmara, delegado escolar, representantes da imprensa local, organização corporativa e párocos), além do episcopado e empresários.

É evidente que a tenacidade do trabalho dos professores e dos agentes oficiais asseguraria, em grande parte, o desenvolvimento satisfatório da Campanha Nacional de Educação de Adultos. O corpo docente fora constituído por professores do ensino primário, regentes de postos escolares e voluntários, com as garantias de competências pedagógica e de idoneidade moral e cívica. Eram os professores que deveriam fazer com que os iletrados ou 
analfabetos se interessassem pela sua recuperação cultural. Eram eles, principalmente, quem levavam a efeito o princípio da educação escolar para todos, nacionalmente. Nas palavras de Dr. Henrique Veiga de Macedo (1953, p. 41 1): "E, felizmente, muitos professores e regentes de postos escolares estão já a dar pelos exemplos de dedicação e de patriotismo que não podem deixar de ser apontados a quem, pela posição que ocupa, deve naturalmente, assumir idênticas responsabilidades."

Os cursos de educação de adultos lescolaridade obrigatória de três anos) - pelo regime da Campanha Nacional de Educação de Adultos a cargo da Direção-Geral do Ensino Primário do Ministério da Educação Nacional no âmbito do Plano de Educação Popular destinados aos grupos de jovens e adultos iletrados ou analfabetos e mais aqueles que não tivessem a $3^{a}$ classe do ensino primário com idade entre 14 a 35 anos -tiveram sua manutenção assegurada pelos recursos do Fundo Nacional de Educação de Adultos, composto por dotação extraordinária do orçamento geral do Estado no valor de quarenta mil contos (40.000.000\$00), além de contibutos de entidades oficiais e particulares (Decreto-Lei n. ${ }^{\circ}$ 38.969, de 27 de outubro de 1952).

No primeiro ano da Campanha Nacional de Educação de Adultos 30 (1952), pela Exposição do Subsecretário da Educação Nacional (1954) como início no dia 2 novembro de 1952 - uma média de noventa e oito mil e quatrocentos e oitenta três (98.483) adolescentes e adultos estava matriculado em três mil e seiscentos e treze (3.613) cursos de educação de adultos nas classes diurnos e noturnos com duas horas diárias letivas. Destes (3.613), novecentos e oitenta e sete (987) cursos funcionaram em empresas da indústria ou do comércio e quinhentos e quinze (515) nas unidades militares do Exército e da Marinha.

No segundo ano da Campanha Nacional de Educação de Adultos (1953), pela Exposição do Subsecretário da Educação Nacional (1954), o número de cursos de educação de adultos em todos os distritos escolares passaria para quatro mil e oitocentos e oitenta (4.880), com uma matrícula de cerca de cem mil (100.000) alunos. Em dezembro de 1953, pelo menos, sete mil e novecentos e sessenta e três (7.963) jovens e adultos foram aprovados nos exames da $3^{a}$ (terceira) classe do ensino primário e mil duzentos e quarenta e três (1 .243) nos exames da $4^{a}$ (quarta) classe do ensino primário, totalizando nove mil e duzentos e nove (9.209) aprovações. 
No terceiro ano da Campanha Nacional de Educação de Adultos (1954), pela Exposição do Subsecretário da Educação Nacional (1954), o número de cursos de educação de adultos em todos os municípios portugueses passaria para cinco mil e seiscentos e trinta e dois (5.632), com uma matrícula de, aproximadamente, cento e vinte e nove mil (129.000) alunos.

Para alfabetizar e melhorar o nível educativo do povo e das próprias conveniências nacionais de ordem humana, cultural, econômica, social, os cursos de educação primária de adultos orientados por dimensões práticas e utilitárias, segundo as opções e finalidades da Campanha Nacional de Educação de Adultos, pelas explicações do Dr. Henrique Veiga de Macedo (1953, p. 15) consagraram uma educação de base supletiva ou fundamental por "[...] adotar a definição feliz do ilustre educador brasileiro professor Lourenço Filho, a que fornece a cada indivíduo os instrumentos indispensáveis da cultura do nosso tempo". Em virtude da estreita associação entre ensino e produtividade, as entidades patronais haveriam de se convencer de que uma razoável escolarização primária trazia grandes vantagens ao trabalhador, pois

[...] desenvolve as suas faculdades de atenção, apura-the o espirito de observação, estimula a sua atividade mental, torna-o mais confiante, mais inteligente e mais apto a aperfeiçoar-se no exercício da profissão. Ela [escolarização] constitui, por isso mesmo, fator importante na produção da riqueza (DECRETO-LEI N. ${ }^{\circ} 38.969$, DE 27 DE OUTUBRO DE 1952, p. 1079).

Uma educação de base supletiva ou fundamental para além da alfabetização e da "educação popular" que ademais, procedesse, melhoria do nível educativo e do ajustamento do jovem e do adulto iletrados na coletividade nacional de conformidade com os despachos do Dr. Henrique Veiga de Macedo (1953) necessariamente, demandou, a elaboração um programa de estudos constituído de leitura e escrita; cálculos aritméticos, história pátria, situação geográfica de Portugal, além de noções de educação moral e cívica, educação familiar, defesa da saúde e higiene, organização corporativa, previdência social, segurança no trabalho, economia doméstica, agricultura e pecuária.

cumprimento desse programa de estudos, indispensavelmente, compreenderia materiais pedagógicos e livros escolares, em particular o livro 
escolar, para dever estimular ao jovem e ao adulto o gosto pela leitura, para ler com regularidade e proveito. No encargo de Subsecretário de Estado da Educação Nacional, Dr. Henrique Veiga de Macedo (1954a, p. 77), com base nas conclusões do VI Seminário Interamericano de Alfabetização e Educação de Adultos (realizado no Brasil em 1949), recomendou que o material de leitura deveria ser: "Prático e relacionado com as necessidades do leitor e de sua família. Simples, de curta extensão e consentâneo com o grau de maturidade mental do leitor. Apresentado em tipo claro e legível."

Aproximadamente setenta mil (70.000) livros foram editados pela Campanha Nacional de Educação de Adultos. À comissão com atribuição de organizar o livro de leitura, particularmente para a $3^{a}$ classe do ensino primário de adultos (que fosse orientado para vida, formativo, informativo, ao mesmo tempo em moldes tradicionalistas e de preceitos católicos), Dr. Henrique Veiga de Macedo (1954a) faria menção ao "sistema" de ensino para adultos do educador e missionário norte-americano Frank Charles Laubach. Esse "sistema" de ensino para adultos propiciaria as bases teóricas para equipe de especialistas planejasse e organizasse as cartilhas para os cursos de ensino primário supletivo da Campanha de Educação de Adultos do Brasil.

Em Portugal, afinal, quais os materiais didáticos e pedagógicos em seus títulos e em seus formatos foram editados e distribuídos para alfabetizar e melhorar o nível educativo de jovens e adultos estudantes dos cursos da Campanha Nacional de Educação de Adultos?

- Livros e os folhetos (70.000 aproximadamente) compuseram os acervos das Bibliotecas Móveis da Campanha Nacional de Educação de Adultos.

- Cartilhas de título - Método português para o ensino rápido e aprazível do ler, escrever e bem falar - autoria de António Feliciano de Castilho - e Cartilha maternal ou arte da leitura - autoria de João de Deus. Segundo Alcoforado (2015), alfabetizar pelas cartilhas de António Feliciano de Castilho e João de Deus e preparar para exames escolares constituíam a metodologia de alfabetização predominante e o objetivo central da campanha de educação de adultos.

- Cartilha de título - Cartilha maternal ou arte da leitura - autoria de João de Deus. Igualmente pelas pesquisas de professor Alcoforado (2015), alfabetizar pela cartilha de João de Deus e preparar para exames escolares constituíam o objetivo e a metodologia da educação de adultos. 
- Livro de título - Educação do adulto iletrado: orientação psicopedagógico e didática - autoria de Francisco de Sousa Loureiro e José Maria Gaspar, respectivamente diretor e professor da Escola do Magistério Primário de Coimbra. Conforme os historiadores da educação Ferreira e Mota (201 1), o referido livro parece haver constituído num curso para educadores de adultos ou mesmo num trabalho de estudo e reflexão para o desenvolvimento dos cursos de educadores de adultos pela semelhança entre os conteúdos desses cursos e a composição do livro.

- Folhetos e cartazes divulgando noções básicas de educação moral e cívica; educação familiar; defesa da saúde e higiene; economia doméstica, agricultura, pecuária; previdência social; segurança no trabalho, organização corporativa e cultura popular.

- Folhetos e cartazes divulgando os cursos de educação de adultos.

- Jornal A Campanha (80.000 exemplares), órgão da Campanha Nacional de Educação de Adultos, dirigido para os professores e agentes de alfabetização e aos recém-alfabetizados.

- Exposições itinerantes referentes à história de Portugal pelas obras de artes.

- Bibliotecas fixas e móveis com coleções de livros e impressos para crianças e adultos.

- Programa de radiofônico difundindo o Plano de Educação Popular e a Campanha de "combate" ao analfabetismo, transmitido pela Emissora Nacional de Radiodifusão.

- As Missões Culturais da Campanha Nacional de Educação de Adultos repartiram-se pelas Missão de Teatrolapresentação de peças especialmente escritas para a Campanha) e a Missão de Cinema.

- A Missão de Cinema mereceu particular atenção no regime da Campanha Nacional de Educação de Adultos pelas projeções de filmes curtos de títulos - As letras descem do céu, Fui ao jardim celeste, Labirinto, Milionário do Riso e a série Zé Analfabeto. Esses e outros filmes para jovens e adultos foram reconhecidos pelo Dr. Henrique Veiga de Macedo (1954a),como imprescindíveis procedimentos e instrumentos de ensino, de cultura e de propaganda do "combate" ao analfabetismo.Para os historiadores da educação Ferreira e Mota (201 1, p. 183), o cinema era entendido pelas autoridades educacionais como um "[...] grande fator de educação e um veículo capaz de coordenar 
vontades para essa luta que nos toca a todos, em particular para chegar às pessoas de letras gordas".

Pelos estudos de Barcoso (2004), a peculiar atenção ao cinema e ao cinema educativo seria devido ao conteúdo dos filmes com apelos para leitura, para escrita e para aritmética, além dos apelos à educação sanitária, à defesa da saúde, à higiene, à previdência social. Na série do Zé Analfabeto, por exemplo, o analfabeto que não sabia ler, escrever e contar, não se encontraria integrado na sociedade moderna. Ao se alfabetizar, imediatamente, passaria a se interessar pela vida escolar dos filhos e a se integrar na sociedade moderna. $\bigcirc$ cinema alteava-se como recurso privilegiado de difusão da cultura popular, de incentivo à alfabetização e à frequência da escola, além da melhoria do nível educativo do povo. Educava-se mediante materiais e recursos diversificados que, por si só, permitia trocas, interferências, intercâmbios. Em verdade, julgamos que havia deveras semelhanças quanto à narrativa do livro Juca Fubá vai à cidade e à narrativa do filme Zé Analfabeto.

No parecer de Barcoso (2004), notória era a satisfação do Subsecretário de Estado da Educação Nacional pelo emprego do filme enquanto recurso pedagógico para educação de base de jovens e adultos.

Em outro trabalho, Araújo e Alcoforado (2015) divulgaram uma pesquisa procedida no Diário de Coimbra (meses de novembro e dezembro de 1952), visando certificar-se dos lugares do Distrito de Coimbra e distritos limítrofes onde foram instituídos os cursos de educação de adultos - ainda em 1952 - convenientemente orientados pelos responsáveis escolares, ao nível distrital e municipal.

Coimbra - Cursos de Educação de Adultos para homens em Alqueidão (Conselho de Figueira da Foz); Carapinheira (Conselho de Montemor-o-Velho); Praia de Mira; Santo Antonio dos Olivais; São João do Campo; Penacova e Oliveira do Hospital.

Coimbra - Cursos de Educação de Adultos para alunas mulheres na delegação da F.N.A.T.

Coimbra - Curso de Educação de Adultos Noturno na Associação de Socorros Mútuos dos Artistas de Coimbra los artistas eram artesãos, sapateiros, pedreiros, serralheiros) e na Casa do Povo de São Pedro de Alva (Concelho de Penacova). 
Coimbra - Cursos de Educação de Adultos em Fábricas (Azulejos Siac; Barbosa e $\mathrm{C}^{a}$; A Ideal Lda; Lufapo e Triunfo). Certamente pelo fato de haver, nessas fábricas, mais de vinte empregados com idade inferior a trinta e cinco anos de idade e sem habilitação de $3^{a}$ classe de ensino primário.

Aveiro - Cursos de Educação de Adultos para mulheres em Santa Maria de Lamas; Fermentelos (Conselho de Águeda); Lourosa de Matos (Conselho de Arouca) e na Sede do Conselho de Estarreja.

Aveiro - Cursos de Educação de Adultos para homens em Fermentelos (Conselho de Águeda); Lourosa de Matos (Conselho de Arouca); Poulena (Conselho de Anedia) e na Sede do Conselho de Estarreja.

Guarda - Curso de Educação de Adultos para homens na Casa do Povo de Alverca da Beira.

Guarda - Cursos de Educação de Adultos para homens na sede do Conselho de Vila Nova de Foz Côa.

Leria - Cursos de Educação de Adultos para homens no Sindicato Nacional de Operários Metalúrgicos de Leiria; Caldeias e na Casa do Povo de Monte Redondo.

Viseu - Cursos de Educação de Adultos para homens em Arno; Alcofra; Armamar; Casa do Povo de Abraveses; Cavernães; Cabanas; Ferreirim; Lajes; Rio dos Moinhos; Carregal do Sal; Castro Daire; Lamego; Mangualde; Moimenta da Beira; Sernancelhe; Satão; Santos Evos; Tabuaço e Vila do Rei.

Viseu - Cursos de Educação de Adultos para mulheres na sede do Conselho de Sernancelhe e na Freguesia de Caporrosa.

A institucionalização dos cursos de educação de adultos nos lugares do Distrito de Coimbra e lugares dos Distritos limítrofes haveriam, portanto, de ser percebidos como instância que difundia a cultura oficial no plano nacional, resultantes de um planejamento centralista que cuidava de garantir as dimensões axiológicas mais caras ao regime vigente. Nos termos do Dr. Henrique Veiga de Macedo (1954a, p. 82 e 83), o extraordinário contributo dos membros das comissões regionais, distritais e concelhias da Campanha Nacional de Educação de Adultos, que por força da imperiosa da interdependência existente entre progresso econômico e nível cultural do povo "[...] deverá [esta] assumir foros de nacional". A Campanha como um autêntico movimento nos domínios da educação popular havia de cooperar "[...] pela palavra, pelo 
exemplo, pela ação, com o melhor espírito patriótico [...]" em concordância com as formulações do Plano de Educação Popular.

\section{Conclusão}

Em seu livro reconhecidamente clássico, Norberto Bobbio (2004, p. 18) afirmava que, somente após a aprovação da Declaração Universal dos Direitos do Homem (1 948), foi que "[...] a humanidade - toda a humanidade - partilha de alguns valores comuns [como o direito dos homens]; e podemos, finalmente, crer na universalidade dos valores [...] no sentido em que universal significa [...] algo subjetivamente acolhido pelo universo dos homens". Para Bobbio (2004, p. 26), o reconhecimento do direito dos homens declarado nas Constituições dos Estados liberais, somente posterior à Segunda Guerra Mundial "[... é que passou da esfera nacional para a internacional, envolvendo pela primeira vez na história - todos os povos".

Decorrente de todos esses acontecimentos históricos - ressaltava Bobbio (2004) - poderia se prever a emergência do desenvolvimento da 36 técnica, da transformação das condições econômicas, da ampliação dos conhecimentos, da intensificação dos meios de comunicação mundialmente e dos recentes interacionamentos sociais e políticas das comunidades internacionais, consequentemente, o conjunto das mudanças na organização da vida humana em geral.

Nessas interdependências de circunstâncias históricas com suas diversas associações com a organização da vida humana em geral, impõe-se, doravante, a reconstrução dos sistemas educacionais de maneira a satisfazer as necessidades prementes de uma nação democrática e as mudanças na organização da vida humana em geral. Portanto, sob os auspícios das resoluções e das recomendações dos organismos internacionais, principalmente da Unesco, as políticas públicas nacionais dirigidas à educação das crianças em idade escolar, simultaneamente às políticas de educação primária supletiva para jovens e adultos iletrados, elevar-se-iam como vitais para aquela organização da vida humana em geral.

Um artigo intitulado A educação no após-guerra de 1944, publicado na Revista Brasileira de Estudos Pedagógicos (certamente escrito por Lourenço Filho), argumentava em proveito da democratização da educação para todos, 
vigorosamente regida por princípios de caráter universal, além da cooperação das nações em matéria de educação pública para a constituição de uma cidadania universal e a consolidação da paz mundial, mais ainda, a integração da humanidade.

Não obstante, os esforços em matéria de educação escolar das instituições internacionais, nacionais, estaduais, locais, associativas e públicas assemelhar-se-iam a uma espécie de planificação educacional para o mundo do após-guerra. Nessa expectativa geral, a educação supletiva e os serviços relativos à formação do adulto como reuniões, cursos de extensão, radiodifusão educativa, bibliotecas e museus, deveriam ser crescentemente expandidos.

Naqueles tempos de após-guerra, a educação primária supletiva do jovem e do adulto iletrado ou analfabeto efetivada nos cursos primários supletivos, planificada e igualmente para todos, em última análise, por suas proposições uniformes e inter-relacionadas de princípios e de preceitos teóricos, necessariamente inovadores de conformidade com as resoluções, recomendações e os atos decisórios dos organismos internacionais, particularmente da Unesco - haveria de incidir naquela organização da vida humana em geral, em especial, na educação das crianças na idade própria.

A educação de todas as crianças na idade própria seria, indubitavelmente, um dos preceitos teóricos e, consequentemente, uma das razões políticas e sociais das Campanhas de Educação de Adultos no Brasil e em Portugal. Pode-se dizer que as teorizações do coordenador do Plano Geral de Ensino Supletivo da Campanha de Educação de Adolescentes e Adultos do Brasil e do coordenador do Plano de Educação Popular de Portugal, dissertavam, exatamente, sobre essa dimensão político-pedagógica das referidas Campanhas.

Pelas teorizações do coordenador do Plano Geral de Ensino Supletivo da Campanha de Educação de Adolescentes e Adultos do Brasil, o professor Manoel Bergström Lourenço Filho, uma das razões especiais, políticas e sociais da educação de jovens e adultos seriam para salvar a própria vida de suas crianças para viver e conviver numa sociedade democrática em sucedânea alteridade. Nessa sua defesa radical, explicitou sua tese:

Os pais analfabetos, em geral, não podem compreender a necessidade da educação de seus próprios filhos. As estatísticas mostram que a baixa frequência às aulas, a descontinuidade dos cursos, ou evasão escolar, está relacionada com o grau de cultura dos pais. 
E ainda não é tudo: nos lares de famílias analfabetas não entram livros e jornais, não há estimulo para o desenvolvimento da culturae, assim, milhares e milhares de crianças, que chegam a aprender alguma coisa na escola, são depois reabsorvidas pelo analfabetismo ambiente (LOURENCCO FILHO, 1949, p. 125).

As teorizações do coordenador da Campanha Nacional de Educação de Adultos como parte do Plano de Educação Popular de Portugal, Dr. Henrique Veiga de Macedo, assemelhavam-se às teorizações do professor Manoel Bergström Lourenço Filho, que já estariam fundamentadas nas resoluções, recomendações e nos atos decisórios dos organismos internacionais, particularmente da Unesco.

Nas comemorações do primeiro ano da Campanha Nacional de Educação de Adultos de Portugal ( 15 de novembro de 1953), Dr. Henrique Veiga de Macedo ensaiava uma teorização acerca da correlação analógica entre a incultura dos adultos e a incultura literária de seus filhos crianças, para assim, advogar o dever do Estado à exequibilidade do princípio da escolaridade obrigatória para toda criança na idade própria, proposição essa inscrita no "coração" das recomendações e resoluções dos organismos internacionais

38 como a Unnesco. Pelos seus ensaios de teorizações:

O analfabeto não tem a noção da vantagem do ensino e entende, na sua visão deformada das coisas, que os filhos não carecem, para as lutas da vida, de quaisquer habilitações literárias. Esta triste realidade torna ainda mais premente a necessidade de fazer alguma coisa para educar os analfabetos, os quais irão, por experiência vivida, convencendo-se do interesse prático em instruir os filhos (MACEDO, 1953, p. 25).

A despeito de a nação portuguesa haver sido integrada como membro efetivo da Organização das Nações Unidas e da Organização das Nações Unidas para a Educação, a Ciência e a Cultura (Unesco), respectivamente em 1955 (14 de dezembro de 1955) e em 1965 (11 de março de 1965), as resoluções, recomendações, boletins, relatórios e publicações especializadas em matéria de educação dos organismos internacionais - principalmente da Unesco - circulavam com constância, mundialmente.

Por conseguinte, as apropriações dos princípios e das proposições de caráter universal em matéria de educação e de educação de jovens e 
adultos por todas as nações eram, absolutamente, bem-aceitas pelos organismos internacionais. Como ressalta o trabalho de Alcoforado (2000, p. 45), a participação na nova ordem mundial, obrigaria todas as nações a uma abertura de adesão aos valores políticos vencedores, em consequência,obrigaria, pois, "[...] a participação em organizações internacionais ligadas à educação e ao trabalho que, por sua vez, implicavam compromissos de desenvolvimento e implementação de políticas educativas".

A socialização de uma educação primária supletiva inovadora mediante uma pedagogia apropriada, parcialmente influiu num certo ajustamento do jovem e do adulto à ordem mundial das coisas estruturantes em devir; parcialmente prolongava-se na educação em geral de seus filhos, uma das razões sociais e políticas caras dos formuladores das Campanhas de Educação de Adultos no Brasil e em Portugal. Logo, muitos dos materiais de ensino e dos procedimentos didáticos, pedagógicos e educativos das Campanhas de Educação de Adultos haveriam de ser dirigidos às crianças, explícita ou mesmo implicitamente.

A despeito das singularidades dos governos e regimes políticos, no Brasil e em Portugal - a educação primária supletiva era convenientemente associada aos preceitos teóricos (equalização das oportunidades educacionais para crianças, jovens e adultos, por exemplo); de materiais de ensino (livros didáticos, cartilhas, manuais, por exemplo); de aprendizados (leitura, escrita, aritmética, história pátria, noções elementares vida social e família; defesa da saúde; trabalho e economia, por exemplo); de procedimentos didáticos, pedagógicos e educativos (bibliotecas, exposições, filmes, por exemplo) e de encargos públicos (Fundo Nacional de Ensino Primário e Fundo Nacional de Educação de Adultos, por exemplo). Tudo isso, necessariamente legitimaria e efetivaria os princípios e as proposições de caráter universal dos organismos internacionais. Há nisso uma dimensão prospectiva da firmeza da reprodução da indissociabilidade do universal e do singular em matéria de educação primária supletiva.

Assim, a magnitude com que se julgavam as políticas o de educação primária supletiva para educar jovens e adultos simultaneamente às políticas educativas para as crianças em idade escolar, que propiciaria, por ser assim, inegáveis interseções de complementaridade com a expectativa da cooperação das nações em matéria de educação pública, para a consolidação de uma cidadania universal e da paz mundial. Além disso, era perceptível a 
integração da humanidade por intermédio do domínio tido por internacional, o território nacional e o plano estadual, municipal, distrital.

\section{Notas}

1 Os delegados do Brasil nessa $1^{a}$ Conferência de Ministros e Diretores da Educação das Repúblicas Americanas foram Manoel Bergstrom Lourenço Filho, Abgar Renault e San Thiago Dantas.

$2 \bigcirc$ governo brasileiro foi representado pelo professor Abgar Renault, Pascoal Carlos Magno (Secretário da Embaixada Brasileira em Londres) e Diógenes Bittencourt Monteiro (Auxiliar do Consulado de Liverpool). Em 13 de junho de 1946, o governo brasileiro criou o órgão nacional da Unesco com a denominação Instituto Brasileiro de Educação, Ciência e Cultura (IBECC), presidido pelo jurista, ensaísta e político Levi Fernandes Carneiro.

3 Este é o terceiro (penúltimo) produto do Projeto Interinstitucional de Cooperação Acadêmica entre a Universidade Federal do Rio Grande do Norte (Centro de Educação) e a Universidade de Coimbra (Faculdade de Psicologia e de Ciências da Educação) para se efetuar no plano de pesquisa de título - A Educação de base primária para idade adulta no Brasil e em Portugal no século XX.

4 Manifesto a minha profunda gratidão à prof. ${ }^{a}$ Dr. ${ }^{a}$ Deane Monteiro Vieira Costa, pelo trabalho de me enviar os documentos da Campanha de Educação de Adultos no Brasil do período de 1947 a 1950.

\section{Referências}

A EDUCAÇÃO no após-guerra. Revista Brasileira de Estudos Pedagógicos, Rio de Janeiro, v. 1, n. 1, p. 60-72, jan. 1944.

A COOPERAÇÃO dos Congregados Marianos. A Ordem, Natal, p. 1. 17 abr. 1947.

ARAÚJO, Marta Maria de; ALCOFORADO, Joaquim Luís Medeiros. A educação para idade adulta no Brasil e Portugal no século XX. In: Congresso Brasileiro de História da Educação, 8., 2015, Maringá. Anais... Maringá: SBHE/Universidade Estadual de Maringá, 2015. Disponível em: http://8cbhe.com.br/anais.

ALCOFORADO, Joaquim Luís Medeiros. Educação de adultos e trabalho. 2000. $219 f$. Dissertação (Mestrado em Ciências da Educação) - Faculdade de Psicologia e de Ciências da Educação, Universidade de Coimbra, 2000.

A educação de adultos em Portugal, na segunda metade do século XX. In: FERREIRA, Maria Salonilde; CABRAL, Marlúcia Barros Lopes; QUEIROZ, Liomar Costa de; IBIAPINA, 
Ivana Maria Lopes de Melo (Org.). Investigação em educação: diversidade de saberes e de práticas. Teresina/Fortaleza: Imprece Editorial, 2015.

ALVES, Gilberto Luiz. O nacional e regional na história da educacional brasileira: uma análise sob a ótica dos Estados Mato-Grossenses. In: Sociedade Brasileira de História da Educação (Org.). Educação no Brasil: história e historiografia. Campinas: Autores Associados, 2001.

BARCOSO, Cristina. $\bigcirc$ Zé analfabeto no cinema. $\bigcirc$ cinema da campanha nacional de educação de adultos (1952-1956). In: FERREIRA, António Gomes (Org.). Escolas, culturas e identidades. Coimbra: Edilaber, 2004.

BRASIL. Decreto-Lei $\mathbf{n}^{\circ} \mathbf{8 6 8}$, de 18 de novembro de 1938. Cria, no Ministério da Educação e Saúde, a Comissão Nacional de Ensino Primário. Disponível em: http://www2.camara. leg.br/legin/fed/declei/1930-1939/html. Acesso em: 7 set. 2015.

Decreto n ${ }^{\circ}$ 19.513, de 25 de agosto de 1945. Disposições regulamentares destinadas a reger a concessão do auxílio federal para o ensino primário. Disponível em: http:// www2.camara.leg.br/legin/fed/decret/1940-1949/html. Acesso em: 7 set. 2014.

Ministério da Educação e Saúde.Portaria n 57, de 30 de janeiro de 1947. Autoriza o Departamento Nacional de Educação a organizar o Serviço de Educação de Adultos. In: Documentos iniciais da Campanha. Rio de Janeiro: Serviço Gráfico do Instituto Brasileiro de Geografia e Estatística, 1947.

Ministério da Educação e Saúde. Relatório das atividades no exercício de 1947, apresentado ao Senhor Ministro da Educação e Saúde, professor Clemente Mariani, pelo professor M. B. Lourenço Filho. In: Serviço de Educação de Adultos. Rio de Janeiro: Serviço Gráfico do Instituto Brasileiro de Geografia e Estatística, 1948.

Relatório das atividades no exercício de 1948, apresentado ao Senhor Ministro da Educação e Saúde, professor Clemente Mariani, pelo professor M. B. Lourenço Filho. In: Serviço de Educação de Adultos. Rio de Janeiro: Serviço Gráfico do Instituto Brasileiro de Geografia e Estatística, 1949.

Relatório das atividades no exercício de 1949, apresentado ao Senhor Ministro da Educação e Saúde, professor Clemente Mariani, pelo Diretor Geral do Departamento Nacional de Educação, professor M. B. Lourenço Filho. In: Serviço de Educação de Adultos. Rio de Janeiro, 1950.

Relatório das atividades no exercício de 1950, apresentado ao Senhor Ministro da Educação e Saúde, professor Pedro Calmon, pelo Diretor Geral do Departamento Nacional 
de Educação, professor M. B. Lourenço Filho. In: Serviço de Educação de Adultos. Rio de Janeiro, 1951.

Ministério da Educação e Saúde. Departamento Nacional de Educação. Planejamento geral da Campanha. Rio de Janeiro: Serviço Gráfico do Instituto Brasileiro de Geografia e Estatística, 1947.

$\mathrm{BOBlO}$, Norberto. A era dos direitos. Tradução Carlos Nelson Coutinho. 7. reimp. Rio de Janeiro: Elsevier, 2004.

CARTA das Nações Unidas e Estatuto da Corte Internacional de Justiça. Assinada em 26 de junho de 1945. Disponível em: http://e25.d32.myftpupload.com/docs/carta_da_onu. pdf. Acesso em: 7 set. 2015.

CLARK, Ana Nolan. Critérios para a seleção ou preparação de material de leitura destinado a adultos que aprendem a ler. In: SEMINÁRIO INTERAMERICANO DE ALFABETIZAÇÃO E EDUCAÇÃO DE ADULTOS, 6; 1949, Petrópolis. Texto datilografado... Petrópolis (Rio de Janeiro): Organização das Nações Unidas para a Educação, Ciência e Cultura/ Organização das Nações Americanas e União Panamericana/Governo Brasileiro, 1949.

I CONFERÊNCIA de Ministros e Diretores de Educação das Repúblicas Americanas. Ata

42 final. Revista Brasileira de Estudos Pedagógicos, Rio de Janeiro, v. 1, n. 2, p. 226-280, jan./jun. 1944.

COSTA, Deane Monteiro Vieira. A Campanha de Educação de Adolescentes e Adultos no Brasil e no Estado do Espirito Santo (1947-1963): um projeto civilizador. 2012. $235 f$. Tese (Doutorado em Educação) - Programa de Pós-Graduação em Educação, Universidade Federal do Espírito Santo, Vitória, 2012.

ENSINO primário supletivo em 1947 e 1948. In: Movimento do ensino supletivo nos anos de 1947 e 1948. Rio de Janeiro: Serviço Gráfico do Instituto Brasileiro de Geografia e Estatística, 1950.

LOURENÇO FllHO, Manuel Bergström. A Campanha de Educação de Adultos. Revista Brasileira de Estudos Pedagógicos, Rio de Janeiro, v. 11, n. 29, p. 5-14, jul./ago. 1947. Educação de base para adolescentes e adultos. Revista Brasileira de Estudos Pedagógicos, Rio de Janeiro, v. 13, n. 37, p. 122-140, set./dez. 1949.

A campanha de educação de adultos. Revista Brasileira de Estudos Pedagógicos, Rio de Janeiro, v. 11 , n. 29, p. 5-14, jul./ago. 1947. 
Educação de base para adolescentes e adultos. Revista Brasileira de Estudos Pedagógicos, Rio de Janeiro, v. 13, n. 37, p. 122-140, set./dez. 1949.

MACEDO, Henrique Veiga de. Despachos de sua excelência, o Subsecretário de Estado da Educação Nacional, Dr. Henrique Veiga de Macedo. In: Plano de Educação Popular. Lisboa: Edição da Campanha de Educação de Adultos, 1953. (v. 5, n. 1).

O problema do analfabetismo. In: Plano de Educação Popular. Lisboa: Edição da Campanha de Educação de Adultos, 1954. (Exposição feita na Conferência de Imprensa e Rádio, realizada, no Ministério da Educação Nacional, em 4 e 5 de novembro de 1953).

Directivas dadas por sua excelência, o Subsecretário de Estado da Educação Nacional. In: Plano de Educação Popular. Lisboa: Edição da Campanha de Educação de Adultos, 1954a. (v. 6, n. 2).

NOTAS e informações do VI Seminário Interamericano de Alfabetização e Educação de Adultos. Educação, Rio de Janeiro, n. 26, p. 29-33, out. 1949.

NUNES, Clarice. História da educação e a comparação: algumas interrogações. In: Sociedade Brasileira de História da Educação (Org.). Educação no Brasil: história e historiografia. Campinas: Autores Associados, 2001.

ORGANIZAÇÃO Educacional Científica e Cultural das Nações Unidas. Convenção que cria uma Organização Educativa, Científica e Cultural das Nações Unidas. Revista Brasileira de Estudos Pedagógicos, Rio de Janeiro, v. 8, n. 22, p. 83-98, maio/ jun. 1946.

PIRES, Maria Adelaide Gregório dos Santos Fonseca. O Plano de Educação Popular ou a legislação de 27 de outubro de 1952 nos primeiros anos de sua execução. Revista Portuguesa de Pedagogia, Coimbra, n. 24, p. 447-518, 1990.

PORTUGAL. Decreto-Lei n. ${ }^{\circ}$ 38.968, de 27 de outubro de 1952. Reforça o princípio da obrigatoriedade do ensino primário elementar, reorganiza a assistência escolar, cria os cursos de educação de adultos e promove uma campanha nacional contra o analfabetismo. Diário do Governo, Lisboa, n. 241, p. 1091. 1952. (Suplemento).

. Decreto-Lei n. ${ }^{3}$ 38.969, de 27 de outubro de 1952. Regula a execução do DecretoLei n. ${ }^{3} 38.968$, que reforça o princípio da obrigatoriedade do ensino primário elementar. Diário do Governo, Lisboa, n. 241, p. 1091. 1952. 
Profa. Dra. Marta Maria de Araújo Universidade Federal do Rio Grande do Norte Departamento de Fundamentos e Políticas da Educação Programa de Pós-Graduação em Educação Lider do Grupo de Pesquisa | Estudos Históricos Educacionais (UFRN | CNPq) Grupo Interdisciplinar de Pesquisa, Formação (Auto)Biografia e Representações (GRIFAR | UFRN | CNPq) E-mail|martaujo@vol.com.br

Prof. Dr. Joaquim Luís Medeiros Alcoforado Universidade de Coimbra Faculdade de Psicologia e de Ciências da Educação Mestrado de Educação e Formação de Adultos e Intervenção Comunitária | Coordenador Grupo de Políticas Educativas e Dinâmicas Educacionais | Centro de Estudos Interdisciplinares do Século XX E-mail | lalcoforado@fpce.uc.pt

Prof. Dr. António Gomes Ferreira Universidade de Coimbra Faculdade de Psicologia e de Ciências da Educação | Diretor Mestrado de Gestão da Formação e Administração Educacional Mestrado de Educação Social e Desenvolvimento Local Mestrado e Doutorado em Ciências da Educação Coordenador do Grupo de Políticas Educativas e Dinâmicas Educacionais, do Centro de Estudos Interdisciplinares do Século XX E-mail | antonio@fpce.uc.pt

Recebido 23 nov. 2015 Aceito 15 dez. 2015 